\title{
ANALYSIS OF THE RED TIDE OCCURRENCE PATTERN WHEN HIGH WATER TEMPERATURE
}

\author{
D. H. Hwang ${ }^{1}$, S. H. Bak ${ }^{1}$, U. Enkhjargal ${ }^{1}$, M. J. Jeong ${ }^{1}$, H. J. Yoon ${ }^{1}$, W.C. Seo ${ }^{2, *}$ \\ ${ }^{1}$ Division of Earth Environmental System Science, Pukyong National University, Yongso-ro 45, Nam-gu, Busan, 48513, \\ South Korea \\ ${ }^{2}$ Department of Materials System Engineering, Pukyong National University, Yongso-ro 45, Nam-gu, Busan, 48513, \\ South Korea - seowc@pknu.ac.kr
}

KEY WORDS: Red tide, SST(Sea Surface Temperature), High Water Temperature, SOM(Self-Organizing Map)

\begin{abstract}
:
In 1982, the red tide caused by Cochlodimium polykrikodies occurred at first in Jinhae Bay in Korea. Since then, it causes serious fisheries damage every year. In 2018 , red tide occurred when high water temperature. We analyzed red tide occurrence pattern when high water temperature. Red tide occurrence date, occurrence area caused by the Cochlodinium polykrikoides were used provided by National Institute of Fisheries Science. SST data were used the GHRSST Level 4 OSTIA data provided by NOAA. The red tide occurred July 14 to September 2 in 2013, July 29 to October 4 in 2014, August 5 to September 23 in 2015, and July 23 to August 8 in 2018 in Korea. The nearest SST data from the red tide occurrence area were extracted. When red tide occurred, SST was $22 \sim 28^{\circ} \mathrm{C}$ in $2013,23 \sim 25^{\circ} \mathrm{C}$ in $2014,21 \sim 27^{\circ} \mathrm{C}$ in $2015,26 \sim 28^{\circ} \mathrm{C}$ in 2018 . SST in 2013 was increasing trend and 2015 was downward trend. SST in 2018 occurred at high water temperatures above $25^{\circ} \mathrm{C}$. The spatial pattern by using the self-organizing map $(3 \times 3$ map), node 4 was the highest frequency(16.9\%). It is considered that it appears at the beginning and end of red tide occurrence. Node 1 was $16.3 \%$ frequency, it showed at the end of 2014 and 2015. SST of node 1 and 4 maintained $22 \sim 23^{\circ} \mathrm{C}$ on the southern sea of Korea. Node 9 was $13.9 \%$, which is the late 2013 and 2018 . Node 9 showed high temperature pattern of more than $26^{\circ} \mathrm{C}$ in the southern sea of Korea.
\end{abstract}

\section{INTRODUCTION}

In 1982, the red tide caused by Cochlodimium polykrikodies(C. polykrikoides) occurred at first in Jinhae Bay in the South Sea of Korea. The red tide caused the serious fisheries damages about \$ 67 million(U.S. dollar) in the South Sea of Korea in 1995. The red tide causes serious fisheries damage every year. It mainly occurs in the South Sea of Korea, which is three times higher than the East Sea of Korea(Lee et al., 2015). In particular, Tongyeong is the region with the highest number of the red tide occurrence in Korea from 1998 to 2015(Yoo et al., 2014). Sea water temperature is the most important causing the red tide, most of the red tide occurs $22 \sim 25^{\circ} \mathrm{C}$ (Yoon, 2005; Oh et al., 2015). In Korea, red tide caused by C. polykrikodies, which is harmful species, is mostly occurs. Especially in 2013, the concentration of $C$. polykrikodies more than 1000 cells $/ \mathrm{ml}$ occurred 45 times(Hwang et al., 2017).

The self organizing map(SOM) is an algorithm for pattern recognition and feature extraction. It is useful for representing and relations of neighborhood using large datasets, also used as a pattern recognition and clustering methods for climate change. It is effective method for maintaining data topology and finding patterns of closely match.

Also, it is possible to find the patterns with similar time series and to extract patterns even if there is noise in the data. The SOM algorithm is also useful to find the patterns by using satellite images which can be used to analyse ocean data such as ocean color, $C$. polykrikodies, sea surface temperature(SST), sea surface height(Liu, Weisberg 2005a; 2005b; 2011; Liu et al., 2006; Uriarte, Martin 2008).

Sea water temperature is the most important factor to the red tide occurrence. In summer, when the red tide occurs, there is a limit to monitor the red tide area by using the satellite images. Because ocean color is used visible spectrum. Therefore, it is suitable to obtain the microwave satellite images which is collected any weather conditions or environment. In this study, it is investigated the relations of SST when red tide occurred, how SST pattern changes by applying SOM technique.

\section{DATA AND METHODS}

\subsection{Data}

In Korea, there is a Red Tide Information System which is able to obtain the red tide occurrence data from the National Institute of Fisheries Science(NIFS). The red tide occurrence data is the red tide occurrence date, red tide occurrence area, sea water temperature, concentrations, latitude and longitude.

SST daily data is provided by NOAA(National Oceanic Atmospheric Administration). For using the gridded data, GHRSST(Group for High Resolution Sea Surface Temperature) level 4 OSTIA data is used. Level 4 data had processed the optimal interpolation.

\footnotetext{
* Corresponding author
} 


\subsection{Methods}

SOM is an unsupervised learning methods based on an artificial neuron lattice. It was first introduced by Teuvo Kohonen of Helsinki University(Kohonen 1982; 2001). In this study, it is processed by using SOM toolbox version 2.0 (http://www.cis.hut.fi/projects/somtoolbox/). SOM have their physical location in the output map which is artificial neurons collections that is participate in a winner-take-all process. The winner-take-all process declares a node with the weight vector which is closest to the input vector, it is called winner. The weight is adjusted to close the input vector. Each node has a neighbors. Neighbor weight changes when these nodes win the competition. They do not change equally. As the neighbors move away from the winner, their weights change small. This process is repeated for each input vector(Kim, 2005).

\section{RESULTS}

Comparing in the recent red tide occurrence and SST pattern, Red Tide Information System provided by NIFS is used. Table 1 shows the red tide occurrence and duration from 2013 to 2018. For the following study, set from 2013 because compare the GOCI(Geostationary Ocean Color Imager) Chlorophyll- $a$ images.

The red tide occurred July 14 to September 2 in 2013, July 29 to October 4 in 2014, August 5 to September 23 in 2015, and July 23 to August 8 in 2018 in Korea. The red tide had not occurred in 2016 and 2017. Therefore, red tide occurred for 47 days in 2013, 51 days in 2014, 50 days in 2015, and 18 days in 2018, respectively. Overall, red tide occurred 166 days from 2013 to 2018.

The nearest SST data from the red tide occurrence area were extracted. Distribution of SST is showed in Table 1 . When red tide occurred, SST was $22 \sim 28^{\circ} \mathrm{C}$ in 2013 which was increasing trend. SST was $23 \sim 25{ }^{\circ} \mathrm{C}$ in $2014,21 \sim 27{ }^{\circ} \mathrm{C}$ in 2015 . When 2015 , it was downward trend. SST was $26 \sim 28^{\circ} \mathrm{C}$ in 2018 , which occurred at high water temperatures above $25^{\circ} \mathrm{C}$.

\begin{tabular}{|c|c|c|}
\hline Date & Duration(days) & SST $\left({ }^{\circ} \mathrm{C}\right)$ \\
\hline $2013.07 .14 \sim 09.02$ & 47 & $22 \sim 28^{\circ} \mathrm{C}$ \\
\hline $2014.07 .29 \sim 10.04$ & 51 & $23 \sim 25^{\circ} \mathrm{C}$ \\
\hline $2015.08 .15 \sim 09.23$ & 50 & $21 \sim 27^{\circ} \mathrm{C}$ \\
\hline $2018.07 .23 \sim 08.09$ & 18 & $26 \sim 28^{\circ} \mathrm{C}$ \\
\hline
\end{tabular}

Table 1. Red tide occurrence and duration. SST extracted from the nearest red tide occurrence.

SST is distributed differently in each year, it is determined that there is associated pattern with red tide occurrence. The spatial pattern by using the self-organizing map $(3 \times 3$ map) is showed in figure 1 . Table 2 shows the list of the red tide occurrence data by each node. The highest frequency was node 4(16.9\%). Node 4 was considered that it appeared at the beginning and end of red tide occurrence. Node 1 was $16.3 \%$ frequency, it showed at the end of 2014 and 2015. SST of node 1 and 4 maintained $22 \sim 23{ }^{\circ} \mathrm{C}$ on the southern sea of Korea. Node 2 was $15.7 \%$ when the beginning of the September in 2014 and 2015. There was the high water temperature $\left(26 \sim 27{ }^{\circ} \mathrm{C}\right)$ band far from the southern sea of Korea. Node 9 was $13.9 \%$, which is the late 2013 and 2018. Node 9 showed high temperature pattern of more than $26^{\circ} \mathrm{C}$ in the southern sea of Korea.
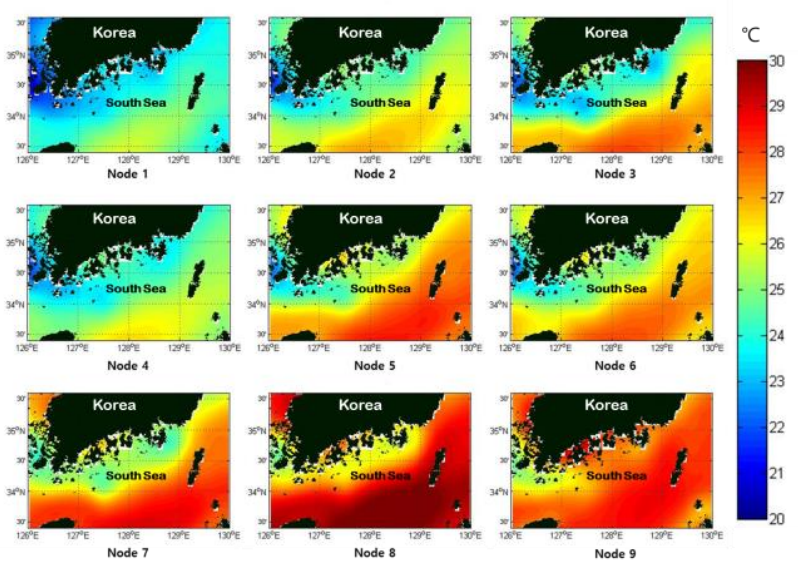

Figure 1. Spatial distribution of SST images when by using SOM algorithm when red tide occurred from 2013 to 2018.

\begin{tabular}{|c|c|c|}
\hline & Date & Frequency $(\%)$ \\
\hline \multirow{3}{*}{ Node 1} & 2014.09.18 2014.09.23 & \multirow{3}{*}{16.3} \\
\hline & 2014.09.26 2014.10.04 & \\
\hline & 2015.09.12 2015.09.23 & \\
\hline \multirow{5}{*}{ Node 2} & 2014.07.29 & \multirow{5}{*}{15.7} \\
\hline & 2014.08.01 & \\
\hline & 2014.08.26 & \\
\hline & 2014.09.04 2014.09.13 & \\
\hline & 2015.08.25 2015.09.06 & \\
\hline \multirow{2}{*}{ Node 3} & $2013.07 .15 \sim 2013.07 .17$ & \multirow{2}{*}{6.6} \\
\hline & 2013.07.23 07.30 & \\
\hline \multirow{7}{*}{ Node 4} & 2013.07 .14 & \multirow{7}{*}{16.9} \\
\hline & 2014.08.04 2014.08.08 & \\
\hline & 2014.08.11 2014.08.12 & \\
\hline & 2014.08.23 2014.08.25 & \\
\hline & 2014.08.27 2014.09.03 & \\
\hline & 2014.09.15 2014.09.17 & \\
\hline & 2015.09.07 2015.09.11 & \\
\hline \multirow{4}{*}{ Node 5} & 2013.07.19 2013.07.22 & \multirow{4}{*}{4.8} \\
\hline & 2013.09 .02 & \\
\hline & 2015.08.11 2015.08.12 & \\
\hline & 2015.08 .15 & \\
\hline \multirow{4}{*}{ Node 6} & 2013.07 .18 & \multirow{4}{*}{7.8} \\
\hline & 2014.07.31 & \\
\hline & 2015.08.13 2015.08.14 & \\
\hline & 2015.08.16 2015.08.24 & \\
\hline \multirow{2}{*}{ Node 7} & 2013.07.31 2013.08.09 & \multirow{2}{*}{6.6} \\
\hline & 2015.08 .05 & \\
\hline Node 8 & 2013.08.10 2013.08.28 & 11.4 \\
\hline \multirow{2}{*}{ Node 9} & $2015.08 .06 \sim 2015.08 .10$ & \multirow{2}{*}{13.9} \\
\hline & 2018.07.23 2018.08.09 & \\
\hline
\end{tabular}

Table 2 . The list of red tide occurrence date by each node and frequency $(\%)$.

\section{CONCLUSIONS AND CONSIDERATIONS}

This study is investigated the relations of SST when red tide occurred, how SST pattern changes by applying SOM technique. At first, red tide occurrence data is obtained by NIFS 
Red Tide Information System. The red tide occurred for 166 days from 2013 to 2016. When red tide occurred, most of SST ranged from 22 to $27^{\circ} \mathrm{C}$. However, in 2018, there were high water temperature over $25^{\circ} \mathrm{C}$

SOM was performed to determine the pattern of SST during red tide occurrence. The highest frequency was node $4(16.9 \%)$, which is considered at the beginning and end of red tide occurrence. Node 1 and 4 maintained $22 \sim 23{ }^{\circ} \mathrm{C}$ on the southern sea of Korea. Node 9 was $13.9 \%$, which showed high temperature pattern of more than $26^{\circ} \mathrm{C}$ in the southern sea of Korea. At each node, we could find SST patterns of beginning and end of red tide.

However, Red Tide Information System has a limitation of data acquisition, because it only cover near from the coast. If we obtain GOCI data or oceanographic data, it will be able to more clearly understand red tide occurrence pattern.

\section{ACKNOWLEDGEMENTS}

This research was a part of the project titled "Establishment and demonstration of red tide detection and prediction system for minimizing red tide damage" funded by the Ministry of Oceans and Fisheries, Korea (PM60650).

\section{REFERENCES}

Hwang, D., Bak, S., Kim, H., Yoon, H., Kang, D., Chung, Y., 2017: The Relation Between the Red Tide Occurrence and the Sea Water Temperature in South Sea of Korea, The 6th Int. Conference on Next Generation Computer and Information Technology, 132-136.

Kim., D., 2005. Neural networks theory and applications 1, Jinhan M\&B, 1st ed., Seoul, Korea.

Kohonen, T., 1982: Self-Organized Information of Topologically Correct Features Maps, Biological Cybernetics, 43, 59-69.

Kohonen, T., 2001. Self-Organizing Maps, Springer Series in Information Sciences, 30, 3rd ed., Springer-Verlag.

Lee, M. O., Kim, B. K., Kim, J. K., 2015: Marine Environmental Characteristics of Goheung Coastal Waters during Cochlodinium polykrikoides Blooms. Journal of the Korean Society for Marine Environment and Energy, 18(3), 166-178.

Liu, Y., and Weisberg, R. H., 2005a: Ocean Currents and Sea Surface Heights Estimated Across the West Florida Shelf, Journal of Physical Oceanography, 37, 1697-1713.

Liu, Y., and Weisberg, R. H., 2005b: Patterns of ocean current variability on the West Florida Shelf using the self-organizing map, Journal of Geophysical Research, 110, C06003.

Liu, Y., Weisberg, R. H., Mooers, C. N. K., 2006: Performance evaluation of the self-organizing map for feature extraction, Journal of Geophysical Research, 111, C05018.

Liu, Y., and Weisberg, R. H., 2011: A Review of SelfOrganizing Map Applications in Meteorology and
Oceanography, Self Organizing Maps - Applications and Novel Algorithm Design, edited by J. I. Mwasiagi, InTech, Rijeka, Croatia, 253-272.

Oh, S., Park, J., Yoon, H., 2015: Prediction of Red Tide Occurrence by using Oceanic and Atmospheric Data by Satellite. Journal of the Korea Institute of Electronics Communication Sciences, 10(2), 311-318.

Uriarte, E. A., and Martin, F. D., 2008: Topology Preservation in SOM, World Academy of Science, Engineering and Technology, 21, 991-994.

Yoo, S., Son, Y. B., Kim, S., Lee. S., Kim Y., 2014. Korea Institute of Science and Technology Information: A Study on the Detection and Likelihood Assessment of HAB outbreaks using Big Satellite Databases. Korea Institute of Science and Technology Information, Ansan, Korea.

Yoon, H., 2005: Meteorological Information for Red Tide : Technical Development of Red Tide Prediction in the Korean Coastal Areas by metrological Factors. The Korean Institute of Maritime Information and Communication Sciences, 9(4), 844853.

Revised August 2019 